\title{
SEGMENTING CHILDREN'S ACTIVE SCHOOL TRAVEL BEHAVIOUR: INSIGHTS ON CAREGIVERS' PERCEIVED RISKS AND SOCIAL NORMS
}

\begin{abstract}
Purpose Active school travel (AST) programmes aim to change commuting behaviour to improve children's physical and mental health. However, very limited health education programmes for children use segmentation to create tailored solutions that understand the specific characteristics of each group of children and their caregivers in order to yield better results. The aim of this study is to use a statistical segmentation analysis (two-step cluster analysis) to gain insights on the examination of specific groups to design future health education interventions and campaigns that can improve children's health.

Methodology Guided by the Ecological and Cognitive Active Commuting framework (ECAC), a market segmentation analysis was performed. An online survey was designed to collect data from caregivers of children between 5 and 12 years attending school and responsible for taking the child to and/or from school in Victoria and Queensland, Australia. Using 3,082 responses collected from Australian caregivers of primary school children, two-step cluster analysis was performed.
\end{abstract}

Findings Analysis revealed the most important variables for group formation were previous child walking behaviour, distance from school and caregiver income. Perceived risk of the physical environment was the most important psychographic segmentation variable for group formation, followed by social norms. Four distinct groups with different characteristics were identified from the analysis. 
Originality This is the first study that applies the ECAC framework to perform market segmentation in the active school travel context. Results revealed four market segments that demand different tailored solutions. Findings shed light on how to better design AST interventions and campaigns to promote children's health using segmentation techniques.

KEY WORDS: active school travel, active commuting, physical activity, health behavior, children, perceived risks, social norms.

\section{INTRODUCTION}

Active school travel (AST), which refers to children using active means of transportation such as walking and cycling to commute between school and home, has been proven to improve children's physical health (Larouche et al., 2014; Schoeppe et al., 2013), mental wellbeing (Stark et al., 2019; Ramanathan et al., 2014) and to have a positive impact on the environment (Marshall et al., 2010). Besides the physical benefits such as cardiovascular fitness (Larouche et al., 2014), studies indicate that children that use active transportation to school have a higher degree of activation (mood, alertness and activity) on the trip and during school (Westman et al., 2013; Stark et al., 2019) and have positive emotions during the school trip (Ramanathan et al., 2014). Additionally, AST is incidental which means no additional effort is needed, as well as economical compared to other forms of physical activity for children, where caregivers do not need to pay for physical activity activities. Yet, a decline in AST has been observed in recent years (Lu et al., 2015; Pang et al., 2017a; Rothman et al., 2018). 
Factors that influence children and adolescents' modes of transportation to and from school have been investigated to understand the decline of AST (Lu et al., 2014). As the Rothman et al. (2018) review indicates, the distance to school is the factor most strongly associated with AST. Furthermore, individual, parental and societal factors, including child's age, parents' educational background, income and other income related factors, race and attitudes towards AST, have moderately positive associations with AST (Rothman et al., 2018). Moreover, previous research has compared objective factors, such as urban form, to individuals' perceptions of the environment around them, finding that objective factors have a stronger and more direct relationship with children's AST behaviour (Lu et al., 2014). Another recent review also found that AST was associated positively with safety, walkability and neighbourhood social interactions and, in line with the literature, negatively associated with travel distance and car ownership (Ikeda et al., 2018). More importantly, factors affecting AST include individual caregivers and parents perceptions. For instance, parent attitudes toward AST have shown a moderate relationship with AST (Rothman et al., 2018). Parental concerns about road safety issues are an important barrier to children's active commuting behaviour (Pang et al., 2017b). Thus, parents or caregivers 'attitudes towards AST play a main role in their children's AST behaviour, where parents decide if they will allow or promote their children walking to school depending on these multiple factors.

Behavioural theories are increasingly used to explain health behaviours to understand their determinants and create more effective health interventions (Tuti et al., 2017; Prestwich et al., 2014). Behavioural theories aid in identifying factors that influence behaviour change 
for different groups or audiences (Schuster et al., 2015; Kubacki et al., 2017a). From a theoretical perspective, social-ecological models propose that behaviour is determined by multiple levels of influence including individual, interpersonal, community, policy and built environment factors (Sallis et al., 2006; Giles-Corti, 2006). Social ecological theory has been frequently applied to design and evaluate AST interventions. Lu et al. (2014) systematic review of factors preventing AST identified that 14 out of 16 included studies used social ecological theory. Nonetheless, social ecological theory has been widely criticised for its lack of sufficient specificity which might lead to overlook crucial personal constructs such as attitudes and intentions, thus, portraying an incomplete picture and possibly biased results (Lu et al., 2014; Pang et al., 2017b). Hence, Sirard and Slater (2008) proposed the Ecological and Cognitive Active Commuting (ECAC) model, which incorporates elements of the social ecological framework, social cognitive theory and McMillan's framework (McMillan, 2007). Figure 1 presents a diagram of the ECAC model and main variables. Sirard and Slater (2008) explain that objective physical environment refers to the built environment on the way to school and includes factors such as traffic, street and intersection density, and neighbourhood walkability. Objective social context refers to the social environment of the neighbourhood, including area-level socialeconomic status and population density (Pang et al., 2017b). Perceived physical environment and perceived social context are influenced by objective physical environment and objective social context respectively and refer to how parents/individuals perceive the objective factors (Sirard and Slater, 2008). The psychosocial mediator refers to the attitudes towards AST (Pang et al., 2017b). 
Figure 1: Ecological and Cognitive Active Commuting (ECAC) model

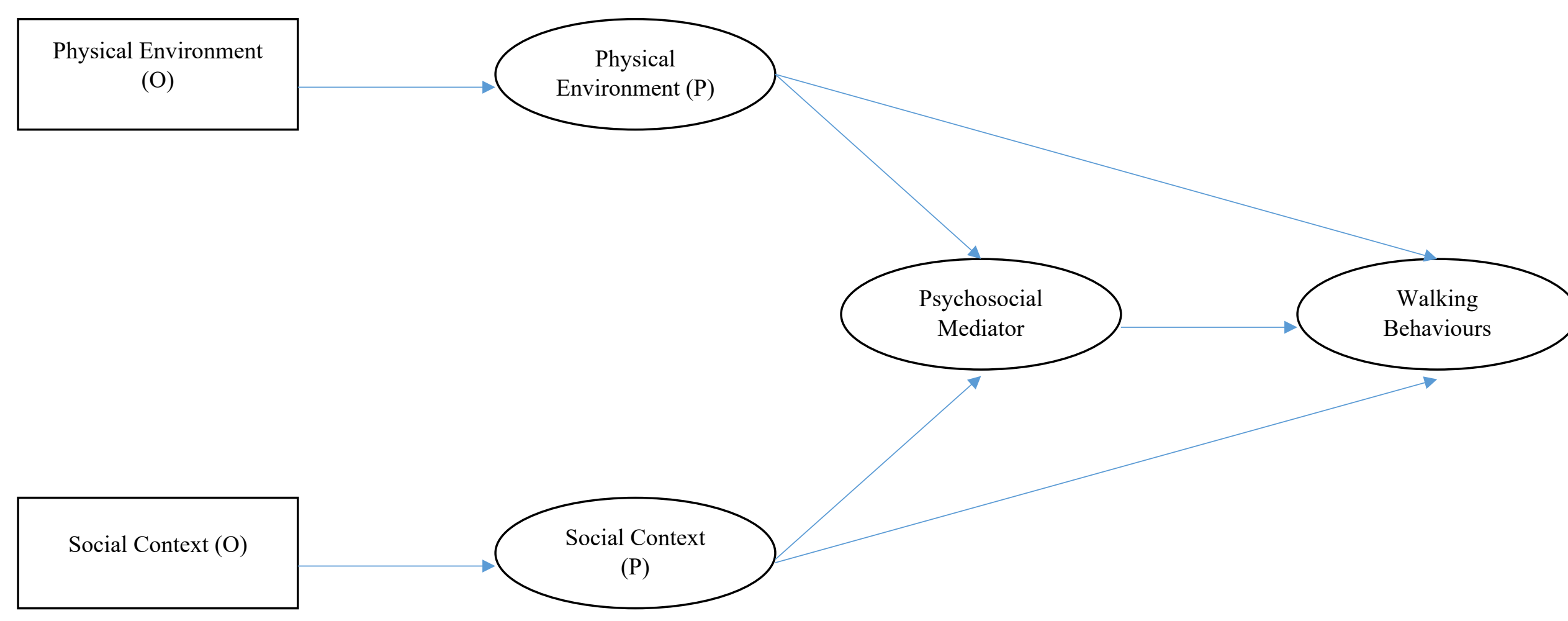

(O): Objective

(P): Perceived 
More recently, Pang et al. (2017b) empirically tested the Ecological and Cognitive Active Commuting (ECAC) model, indicating three main factors associated with AST: attitudes towards AST, perceived risks, and social norms (descriptive and injunctive). Injunctive social norms refer to "what people feel is right based on morals or beliefs" (Berkowitz, 2004), whereas descriptive social norms refer to the specific individual's perceptions of the behaviour of the majority (Cialdini and Goldstein, 2004). Moreover, the ECAC model was identified as the most comprehensive behavioural exploratory model for children's AST behaviours as it offers as high as $53.4 \%$ of variance explained (Pang et al., 2017b). Thus, theoretical evidence of factors that explain AST behaviour may aid to understand individual differences and characteristics of specific groups that influence the uptake of AST for children.

Segmentation is a technique that seeks to develop accurate, robust and meaningful understandings of population subsets that share common characteristics (French, 2017). Thus, segmentation identifies segments (or groups) with common characteristics within a program's target audience, enabling tailored solutions for the specific requirements of each segment (Kubacki et al., 2017a). Segmentation can increase the efficiency and effectiveness of health education and behaviour strategies (Kubacki et al., 2017b). When health behaviour change interventions do not account for individual differences in salient moderating factors, effects might not turn out as expected (Hardcastle and Hagger, 2016). Yet, when segmentation is applied, it has been often based on demographic factors and not on the psychological and behavioural factors shown to have important effects on behaviour (Hardcastle and Hagger, 2016). Moreover, segmentation is crucial for health education 
interventions and campaigns, where resources are often very limited. Recently, social media has enabled behaviour change practitioners to target smaller market segments efficiently and engage with audiences who may have been hard-to-reach in the past (Kubacki et al., 2017a). The use of segmentation to tailor interventions has been increasingly applied in the health behaviour context (Forthofer and Bryant, 2000). More specifically, the literature shows very limited studies that have adopted psychographic segmentation applied to health behaviours. Some examples include physical activity (Boslaugh et al., 2005; Staten et al., 2006), food choice (Byrd-Bredbenner and Abbot, 2008), obesity (Wills et al., 2015), anti-smoking (Walsh et al., 2010), electricity conservation (Gray and Bean, 2011) and HIV prevention (Rimal et al., 2009). However, segmentation is still underutilized in health education and behaviour programmes that target children (Schuster et al., 2015). Exceptions of interventions for children that applied segmentation and targeting efforts are Power Play (Keihner et al., 2011) and Team Nutrition (Levine et al., 2002), designed to improve eating behaviour and physical activity. This study aims to contribute to address this gap in the literature using an approach focused on behavioural theory applied to segmentation techniques.

In a recent study, Schuster et al. (2015) applied segmentation to gain insight into changing AST behaviour in children, revealing three distinct segments of caregivers differentiated by 14 geographic, demographic, psychographic and behavioural variables. Yet, this study employed the Theory of Planned Behaviour (TPB) (Ajzen, 1991), that has shown to explain only $32 \%$ of the variance in physical activity intentions and $28 \%$ of behaviour itself, applied in the context of adults (Rhodes and Courneya, 2003). The purpose of the current study is 
to use a similar method to Schuster et al. (2015), the two-step cluster analysis approach, to gain insights on the examination of market segments in order to design future interventions and campaigns for caregivers and children to better improve children's health. In contrast to the previous AST segmentation study (Schuster et al., 2015), this research employs the novel ECAC theoretical framework, that has been identified as the most comprehensive behavioural exploratory model for children's AST behaviours (Pang et al., 2017b). Two main research questions guide this study:

RQ1: What are the main ECAC model variables that influence caregiver's and their children's walking to school behaviour?

RQ2: What are the main segments that differentiate caregiver's and their children's walking to school behaviour?

\section{METHOD}

\section{Target population}

The target population for this research was caregivers (e.g., parents, grandparents) responsible for getting a child to and/or from school in Victoria and Queensland, Australia. An eligibility screening question was placed at the beginning of survey asking whether the respondent was a carer of primary school students. No geographic or demographic constraints were added as a comprehensive group of respondents was expected in this study. Victoria and Queensland were selected due to their large population sizes as well as similar cultural and economic backgrounds.

\section{Online survey}


Ethical approval was obtained through university ethics committee. An online survey was designed to collect data from caregivers of children between 5 and 12 years attending school and responsible for taking the child to and/or from school in Victoria and Queensland, Australia. Survey links were shared through university owned mail lists and social media advertising (Facebook geo-targeted ads).

\section{Sample}

The survey collected a total of 3,082 responses. Out of the 3,082 responses, 2,545 were from Victoria and 537 were collected in Queensland.

\section{Measures}

ECAC model components were measured using 7-point Likert scales. Objective physical environment is measured by Walk Score (2021), which measures the walkability of any address between 0 and 100 . Walk Score was calculated based on the walking routes to nearby amenities, population density, road metrics such as block length and intersection density. Walk Score has been used in environmental studies such as Gilderbloom and Meares (2020) and Gilderbloom and Meares (2020). Objective social context was measured by the Socio-Economic Index for Areas (SEIFA) score (Australian Bureau of Statistics, 2016). SEIFA scores include diverse attributes such as income levels, employment status, educational background, occupation and household arrangement. Perceived physical environment was represented by perceived risks, including danger of streets, traffic, crime, proximity, and difficulty. Data that was used to calculate the SEIFA score were collected by ABS to ensure reliability and validity. SEIFA scores have been widely used in health promotion and physical activities studies such as Agostini et al. (2018), Gearon et al. (2020) and Gunn et al. (2020). Both the walking behaviour and the 
distance to schools were self-reported in the survey (see supplementary file). Perceived social context was operationalised by descriptive and injunctive norms, which measures the perceived social norms of walking to school behaviour, including the general public and the people important to caregivers. The psychosocial mediator construct was measured by eight attitudinal items about the walking to school behaviour.

\section{Data Analysis}

ECAC constructs for this analysis were validated in a previous study (Pang et al., 2017b) using confirmatory factor and subsequent path analysis in SPSS AMOS Ver. 23. Good convergent scores were observed using Cronbach's alpha across all multi-item factors. For this study, a two-step cluster analysis was undertaken using the five ECAC measures and additional demographic segmentation variables for carers and children. A total of 16 analysed variables covered the four bases of segmentation: geographic (approximate distance from school, Walk Score), demographic (SEIFA score, caregiver employment, education, income, number of cars, gender, age, number of children, child age and gender), psychographic (perceived risks, descriptive and injunctive norms, attitudes), behavioural (walking behaviour).

Cluster analysis is a term describing a range of statistical techniques for classifying individuals or objects into distinct groups or "clusters" with maximal intragroup homogeneity and maximal intergroup heterogeneity (Hair et al., 2006). The main advantages of this method are the ability to manage both categorical and continuous variables, automatic selection of the number of clusters, and the ability to analyse large datasets (Norusis, 2005; Ballestar et al., 2018). Two-step cluster analysis is appropriate in situations where the sample size is large and where the researcher does not know in advance 
the number of clusters required to adequately segment the sample (Norusis, 2005). Similar to previous segmentation studies (Lamont and Jenkins, 2013; Tkaczynski et al., 2010), two-step cluster analysis was appropriate for this study because of the large sample size $(n=3,082)$ and because there was no previous basis for specifying the number of clusters required to segment the sample. Moreover, two-step cluster analysis is considered most appropriate for market segmentation and has been widely used in health behaviour studies (Dietrich et al., 2015; Tkaczynski, 2017), as well as to the context of this study - children's walking behaviour (Schuster et al., 2015).

\section{RESULTS}

Two-step cluster analysis in SPSS 25 was used to group carers based on their attitudes and preferences on their children walking to school behaviour. A four-cluster solution was achieved from the data set using 16 segmentation variables including the five ECAC model variables. Evaluation of the consistency of the clustering structure was performed using silhouette validation (Rousseeuw, 1987), which measures cohesion between elements within a cluster and separation between clusters. The silhouette measure of cohesion and separation is an index ranging from -1 to 1 , where -1 means that the model is poor and 1 means that the model is optimal (Rousseeuw, 1987). The silhouette measure reflects the efficacy of a cluster solution in maximizing within-cluster homogeneity and maximizing between-cluster heterogeneity (Kaufman and Rousseeuw, 2009). The silhouette measure of cohesion and separation was 0.1 which is commonly used in segmentation studies (Schuster et al., 2015; Lamont and Jenkins, 2013). The four clusters varied significantly across the 16 segmentation variables, as validated by chi-square and one-way ANOVA tests. 
The importance predictor measures the relevance rather than the accuracy of the model (Ballestar et al., 2018). An importance rating of between 0.8 and 1.0 indicates the variable was highly important to cluster formation, whereas a rating of between 0.0 and 0.2 indicates the variable was less important (Norusis, 2005). In the present study, cluster formation was determined by nine highly important variables: walking behaviour (importance $=1.0$ ), distance to/from school (importance $=1.0$ ), income (importance $=0.66$ ), perceived physical environment (importance $=0.64)$, employment (importance $=0.42)$, perceived social context (importance $=0.40$ ), number of vehicles (importance $=0.34$ ), caregiver gender (importance $=0.29)$ and caregiver education (importance $=0.25)$. Furthermore, cluster size was relatively homogeneous, ranging from 473 to 693 . Please refer to Table 1 for more details on each cluster.

Table 1 - Four-cluster solution

\begin{tabular}{|c|c|c|c|c|c|c|}
\hline & $\begin{array}{l}\text { Impo } \\
\text { rtanc } \\
\mathrm{e}\end{array}$ & $\begin{array}{l}\text { Group 1 } \\
21.2 \% \\
\mathrm{n}=473\end{array}$ & $\begin{array}{l}\text { Group 2 } \\
31.0 \% \\
\mathrm{n}=693\end{array}$ & $\begin{array}{l}\text { Group } 3 \\
21.6 \% \\
n=483 \\
\end{array}$ & $\begin{array}{l}\text { Group } 4 \\
26.2 \% \\
\mathrm{n}=586\end{array}$ & $\begin{array}{l}\text { Signi } \\
\text { fican } \\
\text { ce (p) }\end{array}$ \\
\hline $\begin{array}{l}\text { Walking } \\
\text { behaviour }\end{array}$ & 1.0 & $0.88(1.40)$ & $0.14(0.50)$ & $3.46(1.74)$ & $0.63(1.37)$ & $.001 *$ \\
\hline Distance & 1.0 & $\begin{array}{l}1 \mathrm{~km}-\text { less } \\
\text { than } 2 \mathrm{~km} \\
(47.4 \%)\end{array}$ & $\begin{array}{l}5 \mathrm{~km} \text { or more } \\
(42.4 \%)\end{array}$ & $\begin{array}{l}\text { Less than } 1 \\
\mathrm{~km}(78.3 \%)\end{array}$ & $\begin{array}{l}5 \mathrm{~km} \text { or more } \\
(33.3 \%)\end{array}$ & $.001 *$ \\
\hline Income & 0.66 & $\begin{array}{l}\$ 2 \mathrm{k} \text { or more } \\
\text { per week } \\
(34.2 \%)\end{array}$ & $\begin{array}{l}\text { \$2k or more } \\
\text { per week } \\
(46.3 \%)\end{array}$ & $\begin{array}{l}\$ 2 \mathrm{k} \text { or more } \\
\text { per week } \\
(31.5 \%)\end{array}$ & $\begin{array}{l}\$ 600-\$ 799 \\
\text { per week } \\
(21.7 \%)\end{array}$ & $.001 *$ \\
\hline $\begin{array}{l}\text { Physical } \\
\text { Environment } \\
\text { (Risks) }\end{array}$ & 0.64 & $4.19(1.54)$ & $5.27(1.26)$ & $2.62(1.22)$ & $4.84(1.55)$ & $.001 *$ \\
\hline Employment & 0.42 & $\begin{array}{l}\text { Employed } \\
(96.2 \%)\end{array}$ & $\begin{array}{l}\text { Employed } \\
(74.9 \%)\end{array}$ & $\begin{array}{l}\text { Employed } \\
(70.8 \%)\end{array}$ & $\begin{array}{l}\text { Home duties } \\
(51.4 \%)\end{array}$ & $.001 *$ \\
\hline $\begin{array}{l}\text { Social } \\
\text { Context } \\
\text { (Norms) }\end{array}$ & 0.40 & $4.08(1.26)$ & $3.33(1.20)$ & $5.12(1.13)$ & 3.67 (1.32) & $.001 *$ \\
\hline
\end{tabular}




\begin{tabular}{|c|c|c|c|c|c|c|}
\hline $\begin{array}{l}\text { Number of } \\
\text { cars }\end{array}$ & 0.34 & Two $(49.9 \%)$ & Two $(85.3 \%)$ & $\begin{array}{l}\text { Two } \\
(61.1 \%)\end{array}$ & One $(58.2 \%)$ & $.001 *$ \\
\hline $\begin{array}{l}\text { Carer } \\
\text { Gender }\end{array}$ & 0.29 & $\begin{array}{l}\text { Female } \\
(56.7 \%)\end{array}$ & $\begin{array}{l}\text { Female } \\
(97.3 \%)\end{array}$ & $\begin{array}{l}\text { Female } \\
(87.6 \%)\end{array}$ & $\begin{array}{l}\text { Female } \\
(93.0 \%)\end{array}$ & $.001 *$ \\
\hline $\begin{array}{l}\text { Carer } \\
\text { Education }\end{array}$ & 0.25 & $\begin{array}{l}\text { Bachelor } \\
(33.8 \%)\end{array}$ & $\begin{array}{l}\text { Bachelor } \\
(35.8 \%)\end{array}$ & $\begin{array}{l}\text { Bachelor } \\
(25.3 \%)\end{array}$ & $\begin{array}{l}\text { Certificate } \\
(37.7 \%)\end{array}$ & $.001 *$ \\
\hline Carer Age & 0.22 & $\begin{array}{l}40 \text { to } 44 \\
\text { years } \\
(36.4 \%)\end{array}$ & $\begin{array}{l}35 \text { to } 39 \\
\text { years } \\
(45.9 \%)\end{array}$ & $\begin{array}{l}40 \text { to } 44 \\
\text { years } \\
(34.4 \%)\end{array}$ & $\begin{array}{l}35 \text { to } 39 \\
\text { years } \\
(25.3 \%)\end{array}$ & $.001 *$ \\
\hline $\begin{array}{l}\text { Physical } \\
\text { Environment } \\
\text { (Walk } \\
\text { Score) }\end{array}$ & 0.11 & $\begin{array}{l}54.39 \\
(20.82)\end{array}$ & $42.26(22.09)$ & $\begin{array}{l}56.06 \\
(21.04)\end{array}$ & $\begin{array}{l}45.82 \\
(21.76)\end{array}$ & $.001 *$ \\
\hline $\begin{array}{l}\text { Psychosocial } \\
\text { Mediator } \\
\text { (Attitudes) }\end{array}$ & 0.10 & $5.16(1.62)$ & $5.51(1.45)$ & $6.25(1.09)$ & $5.48(1.39)$ & $.001 *$ \\
\hline $\begin{array}{l}\text { Social } \\
\text { Context } \\
\text { (SEIFA } \\
\text { Score) }\end{array}$ & 0.09 & $\begin{array}{l}1015.92 \\
(62.87)\end{array}$ & $\begin{array}{l}1007.84 \\
(57.23)\end{array}$ & $\begin{array}{l}1021.56 \\
(56.06)\end{array}$ & $\begin{array}{l}983.23 \\
(58.68)\end{array}$ & $.001 *$ \\
\hline Child Age & 0.06 & $\begin{array}{l}11 \text { years old } \\
(17.3 \%)\end{array}$ & $\begin{array}{l}7 \text { years old } \\
(19.0 \%)\end{array}$ & $\begin{array}{l}6 \text { years old } \\
(21.7 \%)\end{array}$ & $\begin{array}{l}6 \text { years old } \\
(15.4 \%)\end{array}$ & $.001 *$ \\
\hline $\begin{array}{l}\text { Number of } \\
\text { children }\end{array}$ & 0.03 & $1(65.8 \%)$ & $1(51.5 \%)$ & $1(56.3 \%)$ & $1(65.9 \%)$ & $.001 *$ \\
\hline $\begin{array}{l}\text { Child } \\
\text { Gender }\end{array}$ & 0.01 & $\begin{array}{l}\text { Female } \\
(51.2 \%)\end{array}$ & $\begin{array}{l}\text { Male } \\
(53.1 \%)\end{array}$ & $\begin{array}{l}\text { Male } \\
(56.7 \%)\end{array}$ & $\begin{array}{l}\text { Female } \\
(56.0 \%)\end{array}$ & $.001 *$ \\
\hline
\end{tabular}

* significant positive effects $($ at $\mathrm{p}<.05)$

The four groups found had different characteristics. First, the clusters with shortest distance from school were Group 1 and Group 3. Group 1 with $21.2 \%$ of participants $(\mathrm{N}=473)$, was composed by the caregivers that lived $1 \mathrm{~km}$ or less than $2 \mathrm{~km}$ from school. Yet, they had comparatively lower walking behaviour $(\mathrm{M}=0.88, \mathrm{SD}=1.4)$ than Group 3 with $26.2 \%$ $(\mathrm{N}=483)$ of participants that lived less than $1 \mathrm{~km}$ from school, which had the highest walking behaviour $(\mathrm{M}=3.46, \mathrm{SD}=1.7)$. The majority of Group 1 had a higher income of \$2000 Australian dollars or more per week (34.2\%), had the highest employment from all segments $(96.2 \%)$, owned two cars $(49.9 \%)$, and were aged between 40 and 44 years 
(36.4\%). Interestingly, Group 1 was the segment with most mixed gender of caregivers compared to other segments, with only $56.7 \%$ being female. On the other hand, the majority of Group 3 had a high income of $\$ 2000$ Australian dollars or more per week (31.5\%), a lower employment rate (70.8\%) (yet not the lowest), owned two cars $(61.1 \%)$, and were also aged between 40 and 44 years (34.4\%). Compared to Group 1, Group 3 had predominantly female caregivers with $87.6 \%$ females. Most importantly, perceived risks of the physical environment were very high in Group $1(\mathrm{M}=4.19, \mathrm{SD}=1.5)$ that lived 1 to $2 \mathrm{~km}$ from school, compared to Group 3 that lived less than $1 \mathrm{~km}$ from school and had the lowest perceived risk from all groups $(\mathrm{M}=2.62, \mathrm{SD}=1.2)$. In contrast, Group 1 had slightly lower social norms $(\mathrm{M}=4.08, \mathrm{SD}=1.3)$, compared to Group $3(\mathrm{M}=5.12, \mathrm{SD}=$ $1.1)$.

The groups with longest distance from school were Group 2 and Group 4. Group 2 with $31.0 \%$ of participants $(\mathrm{N}=693)$ and Group 4 with $26.2 \%$ of participants $(\mathrm{N}=586)$, were both composed by a majority of caregivers that lived $5 \mathrm{~km}$ or more from school, with $42.4 \%$ and $33.3 \%$ correspondingly. Group 2 had the lowest walking behaviour from all groups (M $=0.14, \mathrm{SD}=0.5)$ and Group 4 the second lowest with $(\mathrm{M}=0.63, \mathrm{SD}=1.4)$. The majority of Group 2 had a higher income of $\$ 2000$ Australian dollars or more per week (46.3\%), had high employment (74.9\%), owned two cars (85.3\%), were aged between 35 and 39 years $(45.9 \%)$ and were mostly female $(97.3 \%)$. In contrast, Group 4 had the lowest income of all groups with $\$ 600$ to $\$ 799$ Australian dollars per week (21.7\%), the majority were engaged in home duties (51.4\%), owned one car (58.2\%), were aged between 35 and 39 years $(25.3 \%)$ and were mostly female $(93 \%)$. Compared to all other groups where the 
majority of caregivers had a bachelor's degree education level, Group 4 had a majority of caregivers with certificate level (37.7\%). Moreover, both segments that had the furthest distance from school had very high perceived risks of the physical environment. Group 2 had the highest perceived risks of all groups $\mathrm{M}=5.27$ (1.3), and Group 4 also had very high perceived risks $(\mathrm{M}=4.84, \mathrm{SD}=1.55)$. Additionally, both groups had similar scores for social norms: Group $2(\mathrm{M}=3.33, \mathrm{SD}=1.2)$ and Group $4(\mathrm{M}=3.67, \mathrm{SD}=1.3)$.

\section{DISCUSSION}

The purpose of this study is to apply a two-step cluster analysis approach, to gain insights on the examination of caregiver market segments (or clusters) in order to design future interventions and campaigns to better improve children's health. This research employs the ECAC model, to investigate what are the main variables that influence caregiver's and their children's walking to school behaviour, and what are the main groups that differentiate caregiver's and their children's walking to school behaviour.

A four-cluster solution was achieved from the data set using 16 segmentation variables including the five ECAC model variables. Analysis revealed the most important variables for group formation were previous child walking behaviour, distance from school and caregiver income. Perceived risk of the physical environment was the most important psychographic segmentation variable for group formation, followed by social norms. The four distinct clusters identified through the analysis had different characteristics for caregivers and children. 
Our results present valuable practical implications and market insights that may inform future AST programs for children and their caregivers. This study identified four clusters that could be targeted by different health promotion programmes. Consistent with previous research, walking behaviour and distance from school were the most important variables to determine the groups (Schuster et al., 2015; Pang et al., 2017a). Thus, a crucial group to target is residents who live close the school but refuse to walk to school, as they have favourable conditions to achieve behaviour change. Potential solutions include better communication campaigns that provide information on the benefits of walking as well as interventions that promote knowledge and skills to organise everyday schedules. Yet, proximity should not be a barrier to facilitate such behaviours. Different behaviour change strategies and policies such as safety infrastructure (e.g., improving road safety (BringolfIsler et al., 2008), walking routes (Staunton et al., 2003)), drop-off zones (Østergaard et al., 2015), walking school buses (Nikitas et al., 2019; Scharoun Benson et al., 2020), or designated meeting points (Schuster et al., 2015) that may allow children to walk shorter distances in their commute. These initiatives would have to be implemented for Group 2 and 4 due to the crucial barrier that distance represents for them.

In addition to the findings by Schuster et al. (2015), our results revealed that perceived risks of the physical environment were the most important psychological variable for the segmentation (importance $=0.64$ ), which was, however, ignored in the Theory of Planned Behaviour model. Interestingly, we found that Group 2 and Group 4, both of which show very high perceived risks of the physical environment are the residents who live further 
away from the school. In order to achieve changes in any of the groups who live further to the school, our study showed that perceived risks and social norms are crucial variables practitioners and policy makers must consider. Perceived risks could be improved via policy changes (state, council and school) (Gustat et al., 2015) such as speed limits, improving road safety (Bringolf-Isler et al., 2008) and implementing better walkways. Other ways to improve caregiver's perception of safety would be to assign safety officers to patrol around school areas (Pang et al., 2017a) and implement safety information programmes (Mutrie et al., 2002).

Further, social norms can change perceived risks. Contradictory to most of the studies in the AST literature, the social context in our study had less importance in cluster formation (importance $=0.40)$, ranking sixth in comparison. This also differs from Pang et al. (2017b) which explains that social norms are the most dominant variable in the ECAC model (2017). The results show that Group 3 had the highest perceived social norms $(M=5.12$, $\mathrm{SD}=1.13)$ while Group 2 had the lowest social norms $(\mathrm{M}=3.67, \mathrm{SD}=1.32)$ towards children walking to school. This perception of the social context may be attributed in part to the longer distance from school for both clusters. To address perceived risks due to longer distance, social norms are essential for AST programmes. When caregivers perceive that peers and people closer to them accept and/or practice children active school travel they are more likely to let their children walk to school. Thus, health education interventions and campaigns should work with communities and neighbourhoods to reinforce children's walking behaviour (Daniels et al., 2014). For instance, creating schoolbased (or neighbourhood) community events to gather parents to discuss and exchange 
information on the benefits and concerns of walking. This could improve knowledge and beliefs, additionally allowing the creation of walking groups, that may reduce risk perception from caregivers. Other recent AST interventions include outdoor activities in the surroundings of schools and inquiry sessions about urban mobility (Humberto et al., 2021), which observed positive changes in children's perceptions and in caregiver's social norms about transportation.

Social norms are positively associated with the socio-economic status of a local area (Pang et al., 2017b). Consequently, in this study the groups with higher social norms, also have higher income and employment rates. Compared to Schuster et al. (2015), employment (importance $=0.18)$ and income (importance $=0.09$ ) had higher importance in cluster formation (importance $=0.42$ and 0.64 correspondingly). Furthermore, it is relevant to summarize other demographic results important to cluster formation. In regards of number of vehicles, most caregivers owned two cars (groups 1, 2 and 3) while most of Group 4 owned only one car. Additionally, most caregivers were females, while Group 1 was the most diverse, with only $57 \%$ female caregivers. This is an important insight because, according to our ECAC model segmentation, this is one of the two groups most likely to change behaviour. This way, practitioners can tailor any intervention or campaign to both male and female caregivers. Caregiver gender in not considered in Schuster et al. (2015) previous study. 
On the other hand, three ECAC framework constructs were significant but had very low importance in cluster formation. Perceived physical environment (importance $=0.64$ ) and social context (importance $=0.40$ ) were crucial for cluster formation compared to their predictors: objective physical environment (importance $=0.11$ ) and objective social context (importance $=0.09$ ). This may be due to the similarity in scores of the objective measures between groups. These results are in line with Pang et al. (2017b) ECAC model evaluation were the two objective variables are the least important, while perceived risks, social norms and attitudes have higher influence in the model. Nonetheless, in this study, attitudes (psychosocial mediator) had very low importance in cluster formation (importance $=0.10$ ).

The results found in this study demonstrate the importance of psychographic variables applied to segmentation. Results show that the main psychographic variables in this evaluation of the ECAC model deferred to the main variables in TPB applied to active school travel. More specifically, perceived risks of the physical environment was the most important psychological variable for the segmentation using the ECAC model and was not considered in the TPB model. Future research should continue to evaluate the most appropriate theoretical health behaviour model to apply psychographic segmentation to AST. In a study comparing the results of segmentation for physical activity based on either demographic, health status or psychosocial variables alone, or a combination of all three types of variables, results showed that more groups with greater variability in physical activity were created using psychosocial versus health status or demographic variables and that a combination of the three outperformed any individual set of variables (Boslaugh et 
al., 2005). Thus, simple segmentation strategies such as those relying on demographic variables alone may provide little improvement over no segmentation at all. Market segmentation appears to yield more homogeneous subgroups when psychosocial and health status factors are combined with demographic variables (Boslaugh et al., 2005).

This study contributes to the literature in many ways. First, it applies market segmentation into a health behaviour context. Particularly, the research provides insights to improve children active school travel, specifically, addressing caregiver's perceptions. Furthermore, using the ECAC model, this research extends behaviour theory application into market segmentation. Further, this research extends on Schuster et al. (2015) study, comparing the previous TPB approach to the ECAC model and generating new insights. Moreover, this research investigates the value of the ECAC model variables to generate market insights in the AST context.

Finally, there are five major limitations in this study that warrant future research. Firstly, it may present self-reporting bias and a degree of social desirability cannot be excluded. Secondly, purposive sampling of urban regions limits the generalisability of the results to other contexts. Third, the use of the two-step cluster analysis method is novel to AST research, and was only noted once before (Schuster et al., 2015). Further research should compare clustering methods for segmenting AST. This could be tested by using the twostep cluster analysis method and then cluster the same data set using more traditional clustering methods (Tkaczynski et al., 2010). Additionally, cluster analyses limitations should be noted, such as the instability of the cluster solution according to variables entered 
in the models. Further, this study did not examine if the clusters identified would have different responses to behaviour change programmes. Future longitudinal research should investigate differential responses. Finally, this study only applied the ECAC model without making any modifications or improvements, given that this paper took a theoretically driven approach for segmentation. Although having been tested before, the ECAC model still needs to be further developed in terms of its compatibility to the ACT behaviour, its inclusiveness of other environmental, social, or psychographic factors, as well as how the model can be used to predict future behaviours. Future research should consider how to improve the ECAC model therefore its application can be wider and more indicative.

\section{CONCLUSION}

The aim of this study was to use the ECAC model to segment primary school children in terms of factors impacting caregivers' decision for their children to walk to school. Our results revealed that the most important variables for group formation were previous child walking behaviour, distance from school and caregiver income. Perceived risk of the physical environment was the most important psychographic segmentation variable for group formation, followed by social norms. The four market segments identified demand different tailored solutions. Findings shed light on how to better design AST interventions to promote children's health.

\section{REFERENCES}

Agostini A, Lushington K, Kohler M, et al. (2018) Associations between self-reported sleep measures and dietary behaviours in a large sample of Australian school students $(\mathrm{n}=28,010)$. Journal of sleep research 27: e12682. 
Ajzen I. (1991) The theory of planned behavior. Organizational behavior and human decision processes 50: 179-211.

Australian Bureau of Statistics. (2016) Socio-Economic Index for Areas (SEIFA) score 2016. In: Statistics ABo (ed). Australia: Australian Government.

Ballestar MT, Grau-Carles P and Sainz J. (2018) Customer segmentation in e-commerce: Applications to the cashback business model. Journal of Business Research 88: 407-414.

Berkowitz AD. (2004) The social norms approach: Theory, research, and annotated bibliography. Citeseer.

Boslaugh SE, Kreuter MW, Nicholson RA, et al. (2005) Comparing demographic, health status and psychosocial strategies of audience segmentation to promote physical activity. Health Education Research 20: 430-438.

Bringolf-Isler B, Grize L, Mäder U, et al. (2008) Personal and environmental factors associated with active commuting to school in Switzerland. Preventive medicine 46: 67-73.

Byrd-Bredbenner C and Abbot JM. (2008) Psychographic segmentation of mothers of young children using a cluster analysis of food decision influencers. Journal of the American Dietetic Association 108: A66.

Cialdini RB and Goldstein NJ. (2004) Social influence: Compliance and conformity. Annu. Rev. Psychol. 55: 591-621.

Daniels N, Kelly C, Molcho M, et al. (2014) Investigating active travel to primary school in Ireland. Health Education.

Dietrich T, Rundle-Thiele S, Schuster L, et al. (2015) Differential segmentation responses to an alcohol social marketing program. Addict Behav 49: 68-77.

Forthofer MS and Bryant CA. (2000) Using audience-segmentation techniques to tailor health behavior change strategies. American Journal of Health Behavior 24: 3643.

French J. (2017) The importance of segmentation in social marketing strategy. Segmentation in social marketing. Springer, 25-40.

Gearon E, Backholer K, Lal A, et al. (2020) The case for action on socioeconomic differences in overweight and obesity among Australian adults: modelling the disease burden and healthcare costs. Australian and New Zealand journal of public health 44: 121-128.

Gilderbloom JH and Meares WL. (2020) How inter-city rents are shaped by health considerations of pollution and walkability: A study of 146 mid-sized cities. Journal of Urban Affairs: 1-17.

Giles-Corti B. (2006) People or places: what should be the target? Journal of Science and Medicine in Sport 9: 357-366.

Gray DM and Bean B. (2011) Can social marketing segmentation initiatives be used to increase household electricity conservation? Journal of Nonprofit \& Public Sector Marketing 23: 269-305.

Gunn KM, Berry NM, Meng X, et al. (2020) Differences in the health, mental health and health-promoting behaviours of rural versus urban cancer survivors in Australia. Supportive Care in Cancer 28: 633-643.

Gustat J, Richards K, Rice J, et al. (2015) Youth walking and biking rates vary by environments around 5 Louisiana schools. Journal of School Health 85: 36-42. 
Hair JF, Black WC, Babin BJ, et al. (2006) Multivariate data analysis . Uppersaddle River. NJ: Pearson Prentice Hall.

Hardcastle SJ and Hagger MS. (2016) Psychographic profiling for effective health behavior change interventions. Frontiers in psychology 6: 1988.

Humberto M, Moura F and Giannotti M. (2021) Can outdoor activities and inquiry sessions change the travel behavior of children and their caregivers? Empirical research in public preschools in São Paulo (Brazil). Journal of Transport Geography 90: 102922.

Ikeda E, Hinckson E, Witten K, et al. (2018) Associations of children's active school travel with perceptions of the physical environment and characteristics of the social environment: a systematic review. Health \& place 54: 118-131.

Kaufman L and Rousseeuw PJ. (2009) Finding groups in data: an introduction to cluster analysis: John Wiley \& Sons.

Keihner AJ, Meigs R, Sugerman S, et al. (2011) The Power Play! Campaign's School Idea \& Resource Kits improve determinants of fruit and vegetable intake and physical activity among fourth-and fifth-grade children. Journal of nutrition education and behavior 43: S122-S129.

Kubacki K, Dietrich T and Rundle-Thiele S. (2017a) Segmentation in social marketing: why we should do it more often that we currently do. Segmentation in Social Marketing. Springer, 1-6.

Kubacki K, Rundle-Thiele S, Pang B, et al. (2017b) An umbrella review of the use of segmentation in social marketing interventions. Segmentation in social marketing. Springer, 9-23.

Lamont M and Jenkins J. (2013) Segmentation of cycling event participants: A two-step cluster method utilizing recreation specialization. Event Management 17: 391407.

Larouche R, Saunders TJ, Faulkner GEJ, et al. (2014) Associations between active school transport and physical activity, body composition, and cardiovascular fitness: a systematic review of 68 studies. Journal of physical activity and health 11: 206227.

Levine E, Olander C, Lefebvre C, et al. (2002) The Team Nutrition pilot study: lessons learned from implementing a comprehensive school-based intervention. Journal of nutrition education and behavior 34: 109-116.

Lu W, McKyer ELJ, Lee C, et al. (2014) Perceived barriers to children's active commuting to school: a systematic review of empirical, methodological and theoretical evidence. International journal of behavioral nutrition and physical activity 11: 140.

Lu W, McKyer ELJ, Lee C, et al. (2015) Children's active commuting to school: an interplay of self-efficacy, social economic disadvantage, and environmental characteristics. International journal of behavioral nutrition and physical activity 12: 1-14.

Marshall JD, Wilson RD, Meyer KL, et al. (2010) Vehicle emissions during children's school commuting: impacts of education policy. ACS Publications.

McMillan TE. (2007) The relative influence of urban form on a child's travel mode to school. Transportation research part A: policy and practice 41: 69-79. 
Mutrie N, Carney C, Blamey A, et al. (2002) "Walk in to Work Out": a randomised controlled trial of a self help intervention to promote active commuting. Journal of Epidemiology \& Community Health 56: 407-412.

Nikitas A, Wang JY and Knamiller C. (2019) Exploring parental perceptions about school travel and walking school buses: A thematic analysis approach. Transportation research part A: policy and practice 124: 468-487.

Norusis M. (2005) SPSS 14.0 statistical procedures companion: Prentice-Hall, Inc.

Østergaard L, Støckel JT and Andersen LB. (2015) Effectiveness and implementation of interventions to increase commuter cycling to school: a quasi-experimental study. BMC public health 15: 1-8.

Pang B, Kubacki K and Rundle-Thiele S. (2017a) Promoting active travel to school: a systematic review (2010-2016). BMC public health 17: 638.

Pang B, Rundle-Thiele SR and Kubacki K. (2017b) An empirical examination of the ecological and cognitive active commuting framework: A social marketing formative research study. Health Education.

Prestwich A, Sniehotta FF, Whittington C, et al. (2014) Does theory influence the effectiveness of health behavior interventions? Meta-analysis. Health Psychology 33: 465.

Ramanathan S, O'Brien C, Faulkner G, et al. (2014) Happiness in motion: Emotions, well-being, and active school travel. Journal of School Health 84: 516-523.

Rhodes RE and Courneya KS. (2003) Investigating multiple components of attitude, subjective norm, and perceived control: An examination of the theory of planned behaviour in the exercise domain. British journal of social psychology 42: 129146.

Rimal RN, Brown J, Mkandawire G, et al. (2009) Audience segmentation as a socialmarketing tool in health promotion: use of the risk perception attitude framework in HIV prevention in Malawi. American Journal of Public Health 99: 2224-2229.

Rothman L, Macpherson AK, Ross T, et al. (2018) The decline in active school transportation (AST): a systematic review of the factors related to AST and changes in school transport over time in North America. Preventive medicine 111: 314-322.

Rousseeuw PJ. (1987) Silhouettes: a graphical aid to the interpretation and validation of cluster analysis. Journal of computational and applied mathematics 20: 53-65.

Sallis JF, Cervero RB, Ascher W, et al. (2006) An ecological approach to creating active living communities. Annu. Rev. Public Health 27: 297-322.

Scharoun Benson SM, Bruner B and Mayer A. (2020) Encouraging active transportation to school: Lessons learned from implementing a walking school bus program in Northeastern Ontario. Journal of Transport \& Health 19: 100914.

Schoeppe S, Duncan MJ, Badland H, et al. (2013) Associations of children's independent mobility and active travel with physical activity, sedentary behaviour and weight status: a systematic review. Journal of Science and Medicine in Sport 16: 312319.

Schuster L, Kubacki K and Rundle-Thiele S. (2015) A Theoretical Approach to Segmenting Children's Walking Behaviour. Young Consumers 16: 159-171.

Sirard JR and Slater ME. (2008) Walking and Bicycling to School: A Review. American Journal of Lifestyle Medicine 2: 372-396. 
Stark J, Singleton PA and Uhlmann T. (2019) Exploring children's school travel, psychological well-being, and travel-related attitudes: Evidence from primary and secondary school children in Vienna, Austria. Travel behaviour and society 16: 118-130.

Staten LK, Birnbaum AS, Jobe JB, et al. (2006) A typology of middle school girls: Audience segmentation related to physical activity. Health Education \& Behavior 33: 66-80.

Staunton CE, Hubsmith D and Kallins W. (2003) Promoting safe walking and biking to school: the Marin County success story. American Journal of Public Health 93: 1431-1434.

Tkaczynski A. (2017) Segmentation using two-step cluster analysis. Segmentation in social marketing. Springer, 109-125.

Tkaczynski A, Rundle-Thiele S and Beaumont N. (2010) Destination segmentation: A recommended two-step approach. Journal of Travel Research 49: 139-152.

Tuti T, Nzinga J, Njoroge M, et al. (2017) A systematic review of electronic audit and feedback: intervention effectiveness and use of behaviour change theory. Implementation science 12: 1-20.

Walk Score. (2021) Walk Score Methodology. Available at: https://www.walkscore.com/methodology.

Walsh G, Hassan LM, Shiu E, et al. (2010) Segmentation in social marketing: Insights from the European Union's multi-country, antismoking campaign. European Journal of Marketing.

Westman J, Johansson M, Olsson LE, et al. (2013) Children's affective experience of every-day travel. Journal of Transport Geography 29: 95-102.

Wills J, Crichton N, Lorenc A, et al. (2015) Using population segmentation to inform local obesity strategy in England. Health Promotion International 30: 658-666. 